\title{
A PICTORIAL REVIEW OF ONCOPLASTIC AND RECONSTRUCTIVE BREAST SURGERY
}

\author{
Muhammad Asad Parvaiz ${ }^{1}$, Nicola Roche ${ }^{2}$, Jennifer Rusby ${ }^{2}$, Steven Goh ${ }^{3}$, Tapan Sircar ${ }^{4}$ \\ ${ }^{1}$ Department of Breast Surgery, Shaukat Khanum Memorial Cancer Hospital and Research Centre, Lahore, \\ Pakistan, ${ }^{2}$ Department of Breast Surgery, The Royal Marsden NHS Foundation Trust, Sutton, Surrey, \\ United Kingdom, ${ }^{3}$ Department of Breast Surgery, Peterborough City Hospital, North West Anglia NHS Foundation \\ Trust, Peterborough, United Kingdom, ${ }^{4}$ Department of Breast Surgery, New Cross Hospital, The Royal \\ Wolverhampton NHS Trust, Wolverhampton, United Kingdom \\ Received: 20 March 2018 / Accepted: 27 March 2018
}

\begin{abstract}
Oncoplastic surgery (OPS) of the breast has revolutionised the surgical practice in the past few years worldwide and has become an integral part of the breast cancer surgical treatment. OPS blends the principals of good local oncological control with plastic surgery techniques for immediate breast reshaping to provide best cosmetic results as well as oncological safety. It helps in extending the boundaries of breast-conservation treatment to include a group of patients who would otherwise require mastectomy to achieve complete excision of the tumour. OPS is a broad concept that can be used for several different combinations of oncological breast-conserving surgery and reconstructive surgery in the form of breast re-shaping/re-modelling. Careful patient selection and pre-operative planning are key components for the success of any OPS operation for breast cancer. Thorough surgical planning is mandatory including clinical assessment and breast measurements with reference to tumour/breast volume ratios. Mastectomy and total breast reconstruction are an option for patients that cannot have breast conservation. In this article, we provide a pictorial review of various oncoplastic and reconstructive breast operations, explaining the indications, essential principles, concepts and techniques of various surgical procedures.
\end{abstract}

Key words: Breast cancer, oncoplastic surgery, breast reconstruction

\section{Introduction}

Breast cancer lumpectomy also known as wide local excision (WLE) followed by adjuvant breast irradiation is collectively called breast-conserving treatment (BCT). This has become the treatment of choice for early breast cancers where adequate clear surgical margins are achieved with WLE, conserving the breast tissue. ${ }^{[1,2]}$ This is shown to be oncologically safe as far as locoregional recurrence and overall survival are concerned. Moreover, BCT provides cosmetic as well as psychosocial advantages compared to women undergoing mastectomies..$^{[3,4]}$

BCT in up to $30 \%$ patients is shown to produce unsatisfactory cosmetic results due to a combination of

Correspondence: Muhammad Asad Parvaiz, Department of Surgical Oncology, Shaukat Khanum Memorial Cancer Hospital and Research Centre, Lahore, Pakistan.

Email: asadparvaiz@skm.org.pk factors including poor patient selection, large volume resection for big tumours, deviation of nipple-areola complex (NAC), scar contracture and poor incision placement [Figure 1]. ${ }^{[5,6]}$ Oncoplastic surgery (OPS) provides a solution for this. As the name suggests, it has two components: 'onco' - good local control/clear margins, combined with 'plastic' - cosmetic surgery to prevent deformity.

\section{Definition}

Andrew Baildam defined oncoplastic breast surgery as a seamless surgical approach to ablation of breast cancer while concurrently undertaking partial or total breast reconstruction. ${ }^{[7]}$ OPS blends the principals of good local oncological control with plastic surgery techniques for immediate breast reshaping to provide the best cosmetic results as well as oncological safety. ${ }^{[8-13]}$ 


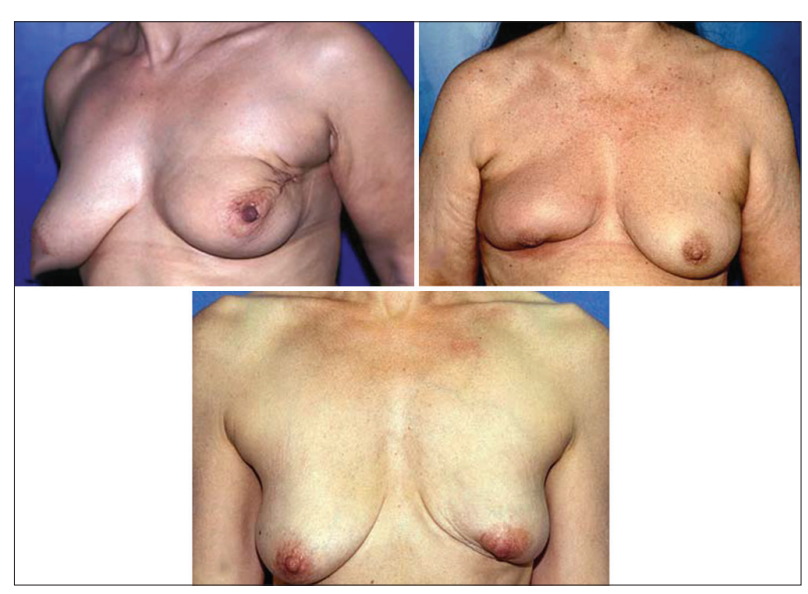

Figure 1: Poor outcomes following traditional breast-conserving surgery. Reprinted with permission [6]

\section{History}

The OPS does not have a long history, a few surgeons from different countries in the 1990s started to utilize oncoplastic breast surgery techniques. ${ }^{[14]}$ The name OPS was first used by Werner Audrescht in Germany. ${ }^{[15]}$ However, Krishna Clough from L'Institut du Sein (The Paris Breast Centre), Paris, France is considered to be the father of modern OPS since his seminal paper in 2003. ${ }^{[16]}$ The concept has gained widespread approval worldwide in the past $10-15$ years. OPS requires the combination of knowledge in three different specialties; surgical oncology, plastic surgery and breast radiology. Formal training is still in various phases of development throughout the world. In the UK, a collaboration between breast and plastic surgeons called Training Interface Group was designed in 2002 . They created nine centrally funded oncoplastic breast fellowship posts, each fellow spending 12 months working in specialist oncoplastic breast units including Royal Marsden Hospital London. Similarly, in the USA, Society of Surgical Oncology approved breast surgical oncology fellowships in 2003 for formal training. ${ }^{[17-19]}$

The purpose of this article is to provide a pictorial review of various oncoplastic and reconstructive breast operations, explaining the indications, essential principles, concepts and techniques of various surgical procedures.

\section{Oncoplastic Breast-conserving Surgery}

\section{Prerequisites}

The OPS should be offered in appropriately selected patients as this involves excessive tissue dissection and mobilisation. Relatively healthy individuals with a good understanding of health and hygiene should be offered such procedures, as risks of complications would be lower in these patients. In general, it is advised to avoid OPS in diabetics, smokers, people with connective tissue disorders, anaemia, malnutrition and poor personal hygiene. However, these are all relative contra-indications and one can offer OPS to such patients, once they have performed multiple OPS procedures along the learning curve. ${ }^{[20,21]}$

Careful surgical planning is mandatory including clinical assessment and breast measurements with reference to tumour/breast volume ratios. Emphasis should be given to proper radiological assessment to know the exact location and extent of the tumour(s). Mammogram and ultrasonogram are essential requirements; however, breast magnetic resonance imaging remains the gold standard and is required in selected patients. computer tomography scan is usually not helpful in the planning of the OPS; however, it has a proven role in detecting incidental breast lesions picked up on imaging carried out for other indications. ${ }^{[22,23]}$

\section{Criteria for BCT}

The OPS has brought a revolution in extending the boundaries of what can be offered with BCT. Previously, it was considered that a breast tumour $>3-4 \mathrm{~cm}$ in size should not be offered BCT. With the advent of the OPS, the actual size of tumour has become a relative factor, more important is the size of the tumour relative to the breast volume as the deciding factor in determining the suitability of BCT. The OPS can be offered in suitable patients every time it is judged possible to achieve complete surgical excision with good cosmesis. It may even be suitable for women with large breasts in whom the tumour is $>5 \mathrm{~cm}$ in size or even multifocal tumours (multiple tumours confined to the same quadrant) or multicentric tumours (multiple tumours in different quadrants) and when large operable tumours have been down-staged by neoadjuvant treatment.

\section{Techniques}

The OPS is broadly done by two different techniques, volume displacement and volume replacement techniques [Table 1]. 


\section{Volume Displacement Techniques}

Volume displacement technique also known as mammoplasty is used when WLE defects are cosmetically closed by mobilisation of breast tissue and breast skin, respectively, known as glandular and dermoglandular tissue flaps. These techniques result in a smaller breast that has cosmetically acceptable shape and appearance. Contralateral symmetrisation surgery is usually required, which can be done simultaneously or at a later stage. ${ }^{[14,16,24-30]}$ Volume displacement techniques include various types of mammoplasties depending on the location of the tumour and breast volume [Table 2].

\section{Inferior pedicle mammoplasty}

Indication: Tumours in the upper half of the breast

Why: Traditional large volume tumour WLE at 12'O clock would leave an upper pole deformity [Figure 2].

Procedure: Wise pattern skin incision, the inferior pedicle is de-epithelialised, cancer WLE is carried out in the upper pole, NAC is advanced upwards in WLE defect based on its blood supply from the inferior and posterior breast tissue attachments. Excessive skin/breast tissue is excised

Table 1: Classification of the oncoplastic surgery

\begin{tabular}{l|l}
\hline Technique & Description \\
\hline $\begin{array}{l}\text { Volume displace- } \\
\text { ment techniques }\end{array}$ & $\begin{array}{l}\text { Filling breast defect by re-modelling } \\
\text { and re-shaping breast tissue from one } \\
\text { area to the other }\end{array}$ \\
\hline $\begin{array}{l}\text { Volume replace- } \\
\text { ment techniques }\end{array}$ & $\begin{array}{l}\text { Filling breast defect by tissue from } \\
\text { outside the breast }\end{array}$ \\
\hline
\end{tabular}

from medial and lateral lower ends to provide appropriate volume redistribution [Figures 3 and 4].

\section{Superior pedicle mammoplasty}

Indication: Tumours in the lower half of the breast

Why: Traditional large volume tumour WLE at 6'O clock would leave a 'birds beak' deformity [Figure 5].

Procedure: Wise pattern skin incision, the superior pedicle is de-epithelialised, NAC is then mobilised with $1 \mathrm{~cm}$ thick underlying breast tissue starting from inferior to superior direction. Cancer WLE is carried out from the inferior pole in the wise pattern. Lateral and medial breast tissue is lifted above the pectoralis fascia by undermining the process and then re-approximated in the midline to fill the WLE defect. NAC is finally shifted upwards for centralisation, based on its blood supply from the superior pedicle [Figure 6].

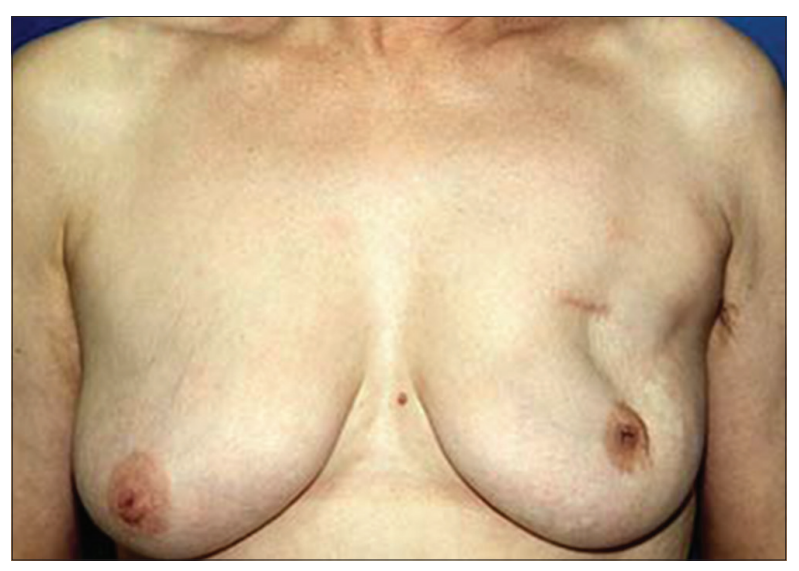

Figure 2: Upper pole deformity. Reprinted with permission [6]

Table 2: Volume displacement techniques

\begin{tabular}{l|l}
\hline Type of mammoplasty & Tumours location within breast \\
\hline Inferior pedicle mammoplasty & Upper half \\
\hline Superior pedicle mammoplasty & Lower half \\
\hline Round block mammoplasty & Periareolar region, sparing the NAC \\
\hline Grisotti advancement rotation flap & Retroareolar tumours, involving the NAC \\
\hline Lateral mammoplasty & Upper outer quadrant \\
\hline Medial mammoplasty & Medial quadrant \\
\hline Horizontal mammoplasty & Upper periareolar \\
\hline Vertical mammoplasty & Infero-medial or subareolar \\
\hline NAC: Nipple-areola complex &
\end{tabular}




\section{Round block/benelli/donut mammoplasty ${ }^{[31}$ RE- VIEW ARTICLE}

Indication: Tumours in periareolar region, but sparing NAC.

Why: Traditional periareolar tumour WLE would leave deviation and deformity of the NAC.

Procedure: Two concentric periareolar incisions $1 \mathrm{~cm}$ apart, intervening skin de-epithelialised, skin flap raised beyond periareolar location over cancer. WLE carried out while preserving the overlying skin, defect filled by mobilizing the adjoining breast tissue. The two periareolar incisions are then sutured together [Figures 7 and 8].

\section{Grisotti advancement rotation flap ${ }^{[32,33]}$}

Indication: Retroareolar tumours involving the NAC.

Why: Traditional central large WLE would leave a 'boxshaped' deformity with a flat breast.

Procedure: A circle similar to NAC diameter is drawn just below the NAC. Lines are drawn from medial and lateral

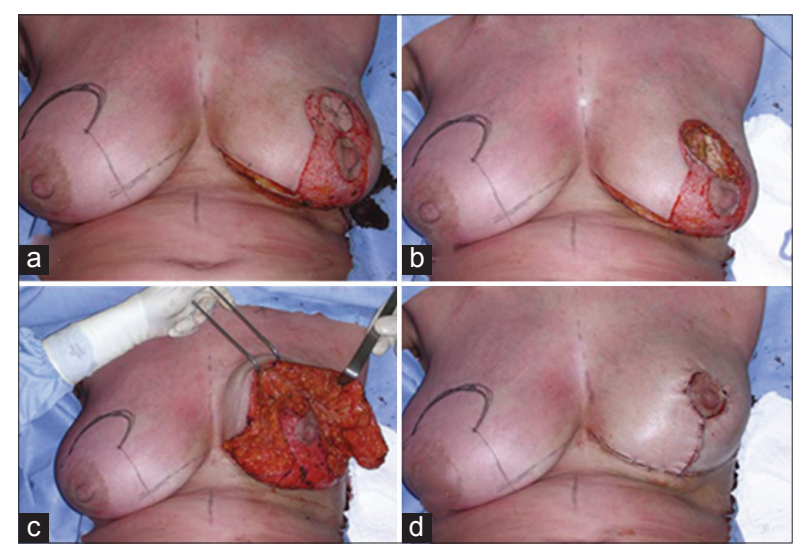

Figure 3: (a-d) Inferior pedicle mammoplasty.

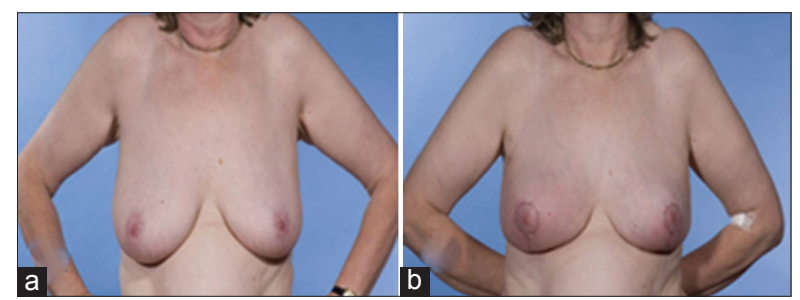

Figure 4: Inferior pedicle mammoplasty. (a) Pre-operative and (b) post-operative sides of the NAC and joined laterally over the inframammary fold (IMF). The intervening skin is de-epithelialised sparing the circle. Cancer WLE is carried out along with excision of the NAC. The breast tissue underlying the skin circle is mobilised over pectoralis fascia and then rotated/advanced into the WLE defect. This flap obtains its blood supply from inferior and lateral pedicle. Nipple reconstruction can be carried out at the same time or later. [Figure 9].

\section{Lateral/racquet mammoplasty}

Indication: Tumours in the upper outer quadrant (UOQ) of the breast.

Why: Traditional large volume tumour WLE from UOQ would leave overlying skin retraction and deviation of NAC [Figure 10].

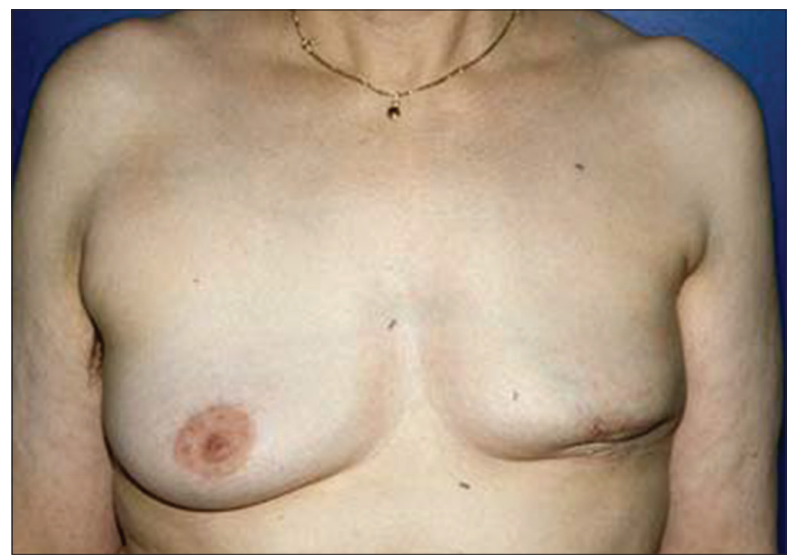

Figure 5: "Birds beak" deformity of the lower pole. Reprinted with permission [6]

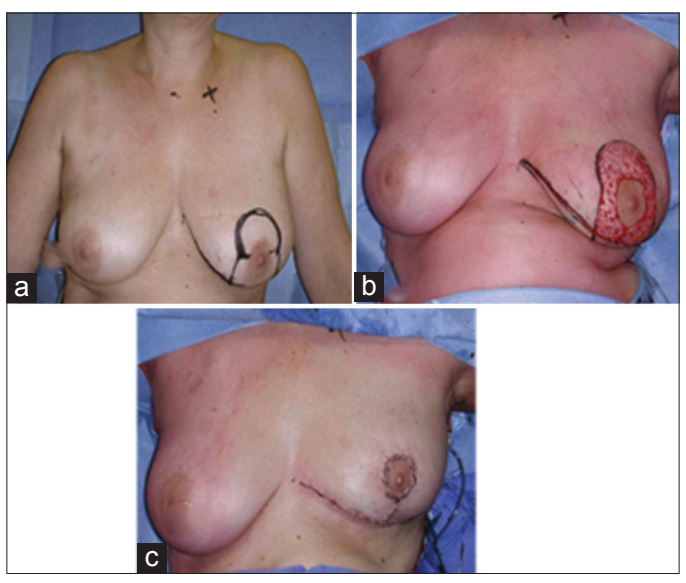

Figure 6: (a-c) Superior pedicle mammoplasty 
Procedure: Concentric ring of periareolar skin medially is de-epithelialised. Cancer WLE in UOQ is carried out with an ellipse of skin from periphery towards periareolar region. Upper and lower dermoglandular flaps are sutured together without undermining or raising skin flaps. The medial periareolar incisions are sutured together, helping to keep the NAC centralised [Figures 11 and 12].

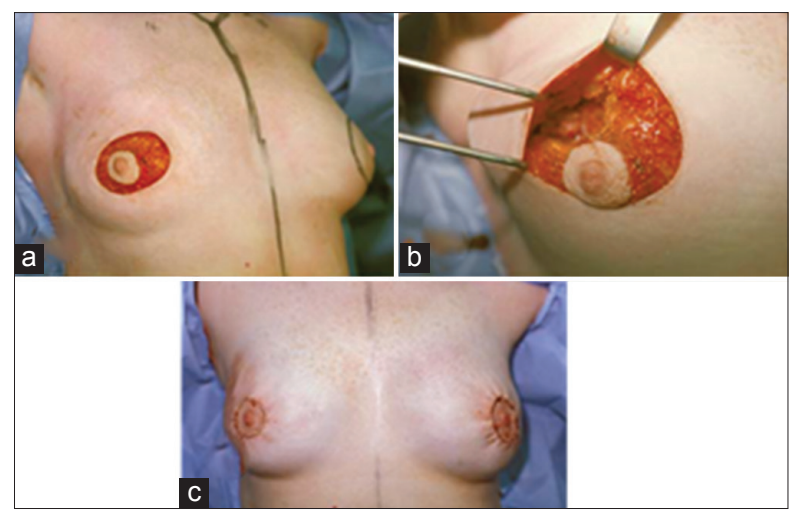

Figure 7: (a-c) Round block/Benelli/Donut mammoplasty Reprinted with permission [6]

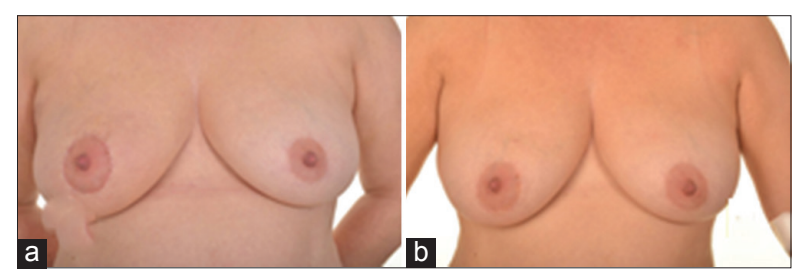

Figure 8: Round block/Benelli/Donut mammoplasty. (a) Preoperative and (b) post-operative

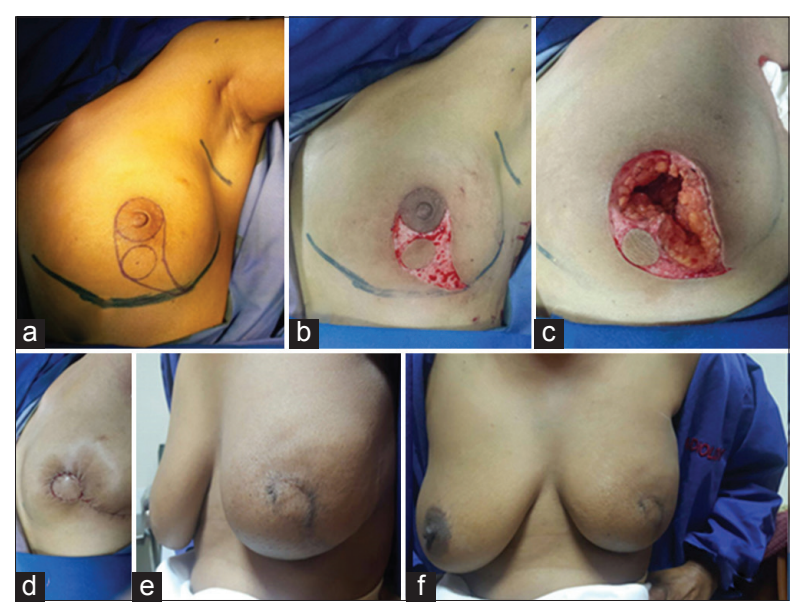

Figure 9: (a-f) Grisotti advancement rotation flap

\section{Medial mammoplasty}

Indication: Tumours in the medial quadrant of the breast.

Why: Traditional large volume tumour WLE from medial breast would leave overlying skin retraction and deviation of the NAC [Figure 13].

Procedure: This is a mirror image of lateral mammoplasty. Concentric ring of periareolar skin laterally is deepithelialised. Cancer WLE in the medial part of the

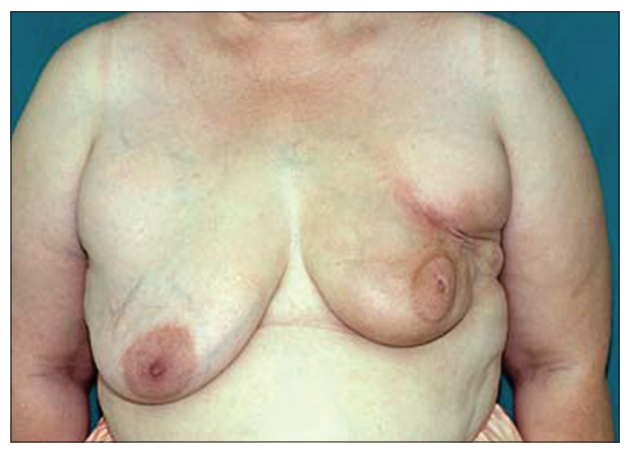

Figure 10: Upper outer quadrant deformity. Reprinted with permission [6]

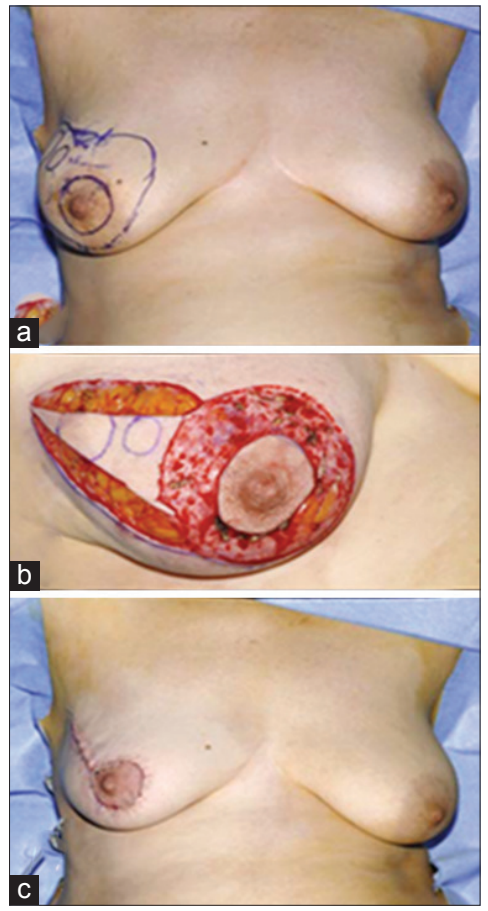

Figure 11: (a-c) Lateral mammoplasty. Reprinted with permission [6] 
breast is carried out with an ellipse of skin from near midline towards periareolar region. Upper and lower dermoglandular flaps are sutured together without undermining or raising skin flaps. The lateral periareolar incisions are sutured together, helping to keep the NAC centralised [Figure 14].

\section{Horizontal/batwing mammoplasty}

Indication: Tumours in the upper periareolar region.
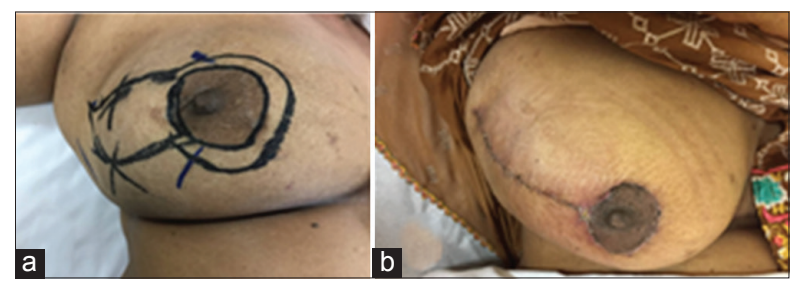

Figure 12: Lateral mammoplasty. (a) Pre-operative and (b) post-operative

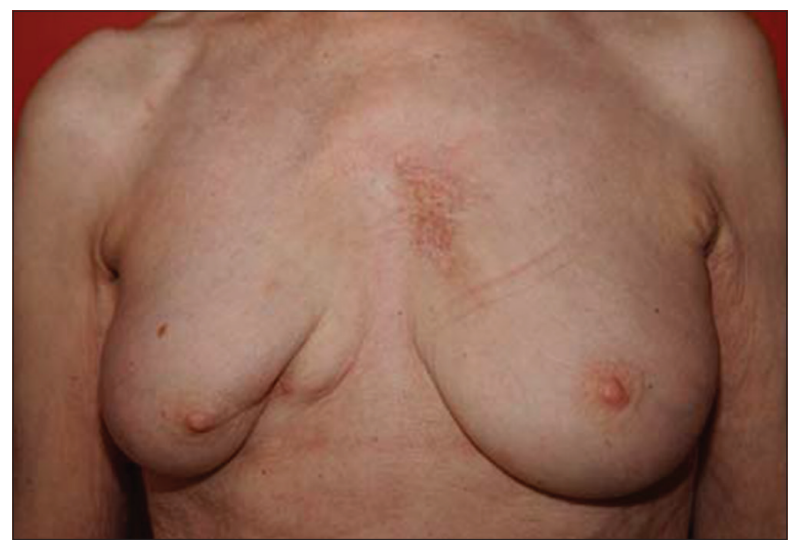

Figure 13: Inner quadrant deformity. Reprinted with permission [6]

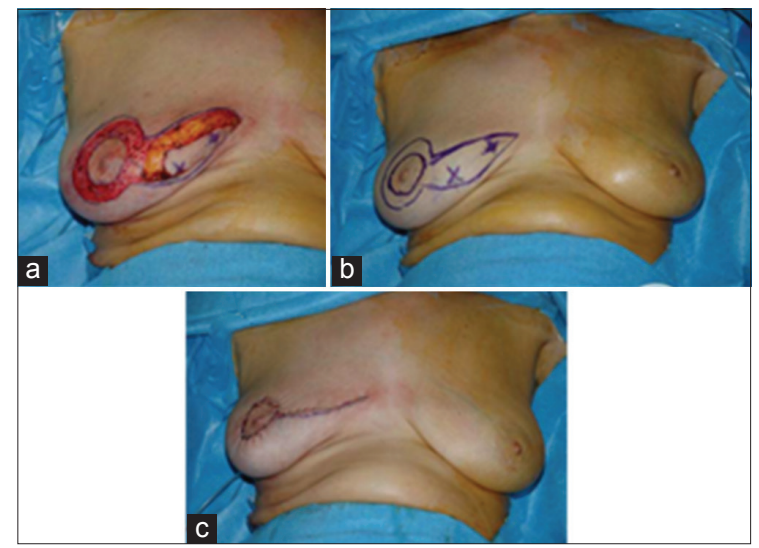

Figure 14: (a-c) Medial mammoplasty
Why: Traditional large volume tumour WLE from this area would leave overlying skin retraction and deviation of the NAC.

Procedure: Horizontal batwing shape incision is made, going above the NAC and wings on both sides. WLE is carried out by excising skin as well as breast tissue and cancer within the marked area. The superior and inferior dermoglandular tissues are approximated [Figure 15].

\section{Vertical/lejour mammoplasty ${ }^{[34]}$}

Indication: Tumours in the inferomedial or subareolar part of the breast.

Why: Traditional large volume tumour WLE through this location would cause central skin in-drawing deformity [Figure 16].

Procedure: Two vertical incisions are made in the form of a vertical ellipse incorporating the NAC as well as cancer. The medial and lateral dermoglandular tissue is approximated with a vertical scar. NAC can be reconstructed at the same time or later [Figure 17].

\section{Volume Replacement Techniques}

Volume replacement techniques are used when local breast dermoglandular tissue is inadequate for cosmetic closure of the WLE defect. Such defects are filled by autologous tissue flaps brought from elsewhere, most commonly from tissues adjacent to the breast. They include both advancement pedicled flaps and free flaps with vascular anastomosis. ${ }^{[16,24,35-38]}$

Volume replacement techniques include various types of flaps depending on the location of the tumour and donor site volume [Table 3].

\section{Latissimus dorsi (LD) flap}

LD flap is the most commonly used volume replacement technique both for partial and total breast reconstruction. There are many variations in its technique. A horizontal ellipse of skin incision is made over the posterolateral thoracic region. Skin, subcutaneous fat and muscle are harvested, based on its blood supply from the thoracodorsal artery. This is then tunnelled through the axilla towards anteriorly by rotating at the front. The flap is then 
Table 3: Volume replacement techniques

\begin{tabular}{l|l|l}
\hline Technique & Type of flap & Based on artery \\
\hline \multirow{2}{*}{ Advancement Flap } & LD flap & Thoracodorsal \\
\cline { 2 - 3 } & TRAM flap & Superior epigastric \\
\hline \multirow{2}{*}{ Perforator advancement flaps } & LICAP flap & Lateral intercostal \\
\cline { 2 - 3 } & TDAP flap & Thoracodorsal \\
\cline { 2 - 3 } & Crescent flap & Superior epigastric \\
\hline Free Flap & DIEP flap & Inferior epigastric \\
\hline
\end{tabular}

LD: Latissimus dorsi, TRAM: Transverse rectus abdominis muscle, LICAP: Lateral intercostal artery perforator, TDAP: Thoracodorsal, artery perforator, DIEP: Deep inferior epigastric perforator

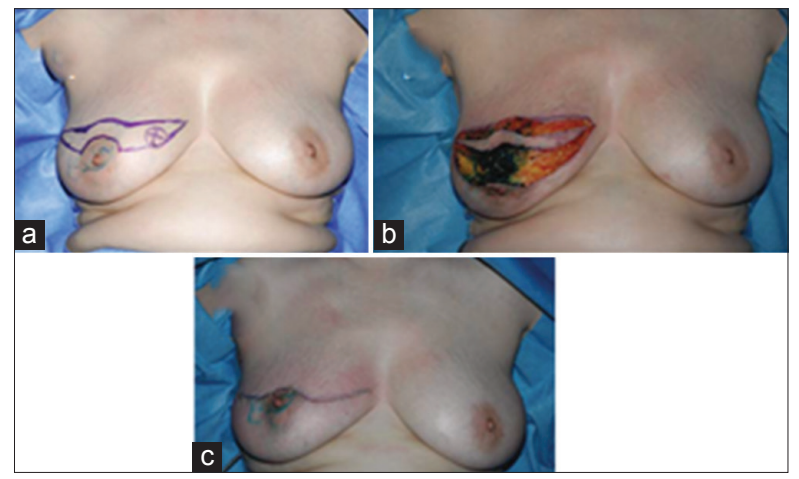

Figure 15: (a-c) Horizontal/Batwing mammoplasty

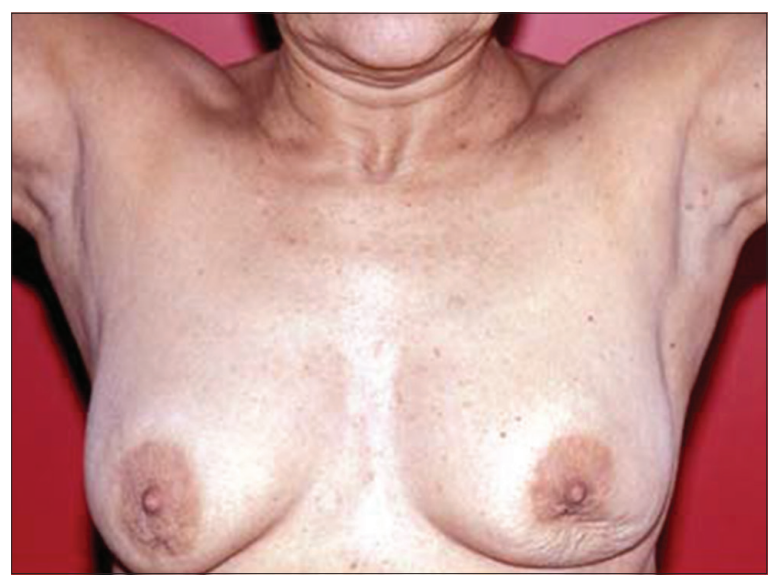

Figure 16: Central deformity. Reprinted with permission [6]

anchored in the defect where WLE has been carried out, providing volume as well as extra skin from the upper back [Figure 18]. ${ }^{[39,40]}$

\section{Perforator flaps}

Perforator flaps are increasingly used for partial breast reconstruction. They contain skin and subcutaneous tissue,

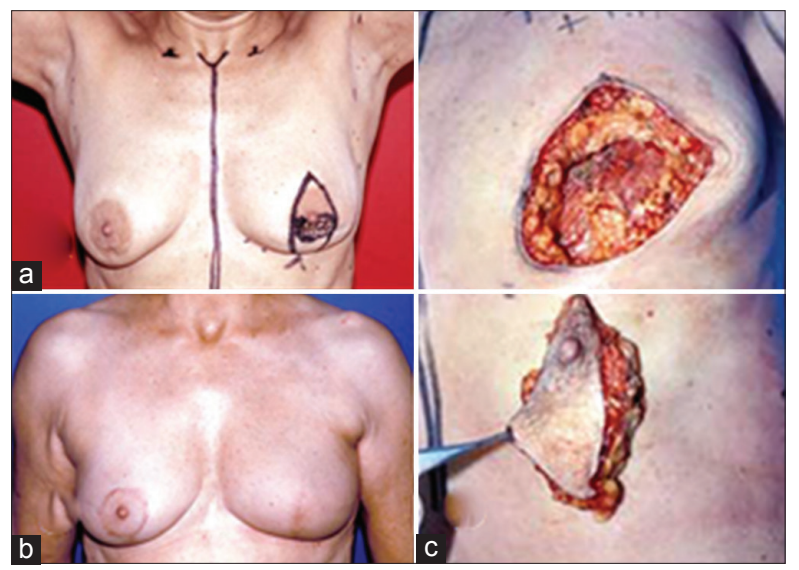

Figure 17: (a-c) Vertical/Lejour mammoplasty Reprinted with permission [6]

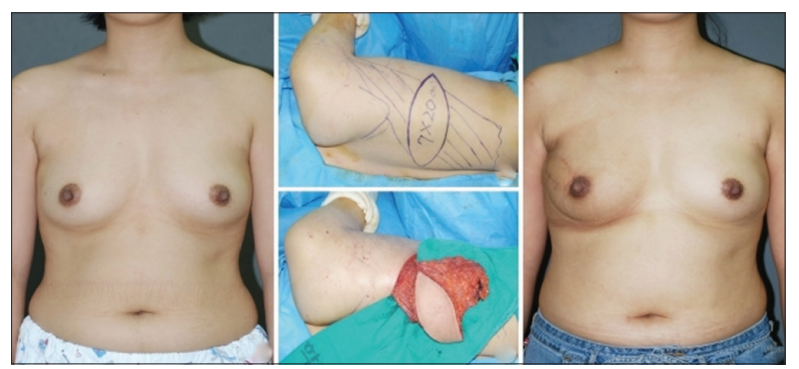

Figure 18: Latissimus dorsi flap as volume replacement for partial breast reconstruction

sparing the underlying muscle and are based on named perforator vessels identified with a hand-held Doppler machine. For lateral quadrant breast volume replacement, lateral intercostal artery perforator or thoracodorsal artery perforator flaps are used [Figures 19 and 20]. For inferior pole defects, crescent flap based on superior epigastric perforator is used. 


\section{Benefits of the OPS}

Losken et al. in their meta-analysis comparing breast conservation therapy alone to the oncoplastic techniques have confirmed the benefits of the OPS. They divided patients into two groups; 3165 patients in the OPS group and 5494 patients in the traditional BCT alone group. Patient and disease variable in the two groups was matching. Tumour size and resection specimen were bigger in the OPS group. The OPS was associated with significantly improved cosmetic outcome $(89.5 \%$ vs. $82.9 \%, P<0.001)$. The positive margin rate was significantly lower in the OPS group $(12 \%$ vs. $21 \%$, $P<0.0001)$. Hence, the re-excision rate was higher in the BCT alone group $(14.6 \%$ vs. $4 \%, P<0.0001)$. Local recurrence rate at mid-term follow-up was better in the OPS group (4\%) than the traditional BCT only group (7\%); however, this difference was not statistically significant $(P=0.08) \cdot{ }^{[41]}$

With the OPS, major volume cancer resection can be achieved without having to do mastectomy, with superior aesthetic consequences. ${ }^{[2-45]}$ The OPS abolishes the necessity for complex delayed corrective procedures

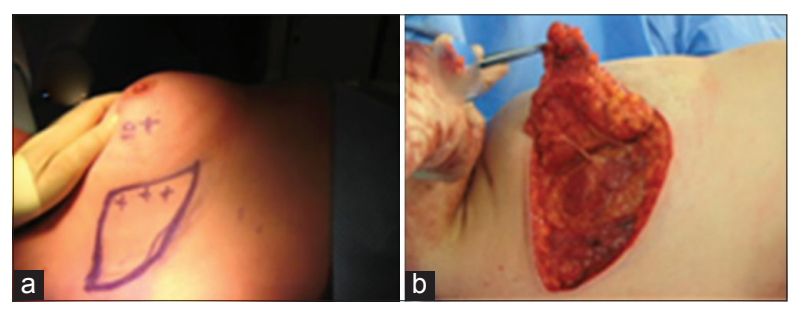

Figure 19: ( $a$ and b) Lateral intercostal artery perforator flap

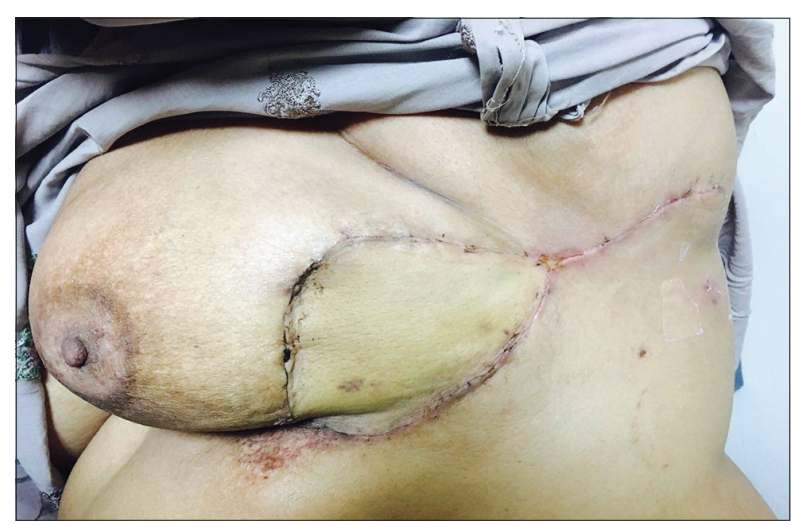

Figure 20: Post-operative picture of lateral intercostal artery perforator flap of WLE deformities worsened by irradiation. ${ }^{[46,47]}$ The OPS also reduces the breast volume, which minimizes radiotherapy related complications [Table 4]. ${ }^{[14,48]}$

\section{Complications of the OPS}

The OPS can be associated with potential complications in a small minority of patients. These complications are in addition to the traditional risks with BCT. Fat necrosis can happen due to excessive tissue mobilisation and possible ischaemia, resulting in lumpy areas causing concern to the patient as well as triggering potential confusion in the reading of subsequent surveillance mammography. Skin flap necrosis is related to tension at wound edges and ischaemia. 5-9\% can have delayed wound healing due to the aforementioned reasons, resulting in possible post-operative adjuvant treatment delays. ${ }^{[6,16]}$

\section{Symmetrisation surgery}

The OPS techniques mostly involve reduction mammoplasties along with the displacement of the NAC, which necessitates contralateral improvisation. Table 5 summarizes the symmetrisation surgery options. These can be offered at the time of index surgery, ideally with two operating teams to minimize the operative time. However, due to potential unpredictable effects of

Table 4: Advantages of the OPS

\begin{tabular}{ll}
\hline 1 & Improved cosmetic outcome \\
\hline 2 & Increase in BCT rate, minimizing mastectomy rate \\
\hline 3 & Reduced rate of re-excision with very wide excisions \\
\hline 4 & Reduced local recurrence rates \\
\hline 5 & $\begin{array}{l}\text { Reduced complications from radiotherapy due to a } \\
\text { smaller volume }\end{array}$ \\
\hline BCT: & Breast-conservation treatment
\end{tabular}

Table 5: Contralateral breast symmetrisation surgery options

\begin{tabular}{l|l}
\hline Surgery & Indications \\
\hline Mastopexy (breast uplift) & Ptotic breast \\
\hline Reduction & Large volume breast \\
\hline Augmentation & Small volume breast \\
\hline Lipomodelling & Scar/contour deformity \\
\hline Nipple reconstruction & Nipple excised with surgery \\
\hline Areola tattooing & Areola excised with surgery \\
\hline
\end{tabular}


adjuvant radiotherapy, most surgeons choose to defer the contralateral symmetrisation to a later stage. ${ }^{[49]}$

Lipomodelling or fat transfer is a relatively new technique, where fat is taken from one part of the body by liposuction, it is processed and then transferred into the recipient breast tissue to help with volume loss and correct contour/scar deformities [Figures 21 and 22].

\section{Mastectomy and Immediate Breast Reconstruction}

Mastectomy is required when BCT cannot be offered, or the patient chooses to have the mastectomy. To improve the quality of life, immediate breast reconstruction can be offered to most patients, where reconstruction is carried out at the same time as mastectomy. However, in some patients delayed reconstruction is preferred, if there is a chance of delay in the adjuvant treatment or if the patient is not ready for reconstruction. Patients are given the details of both the autologous and implantbased reconstruction, involving the body's own tissue and prostheses respectively. There are multiple factors that help in guiding patients towards an appropriate decision, including patients' general health, breast volume, cancer biology, need for adjuvant radiotherapy, donor site availability/volume and patient expectations. ${ }^{[24]}$

\section{Implant-based Breast Reconstruction}

Implant-based reconstruction is especially useful for younger women with small and firm breasts, and it avoids

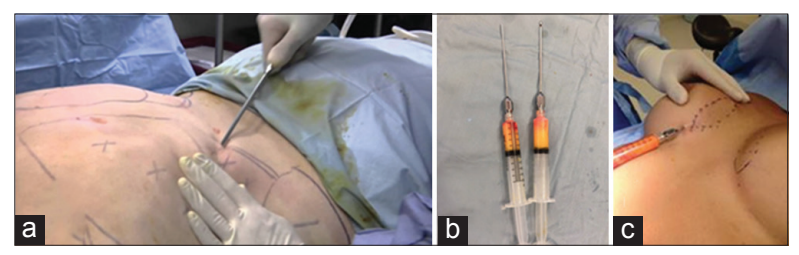

Figure 21: (a-c) Lipomodelling or fat transfer technique

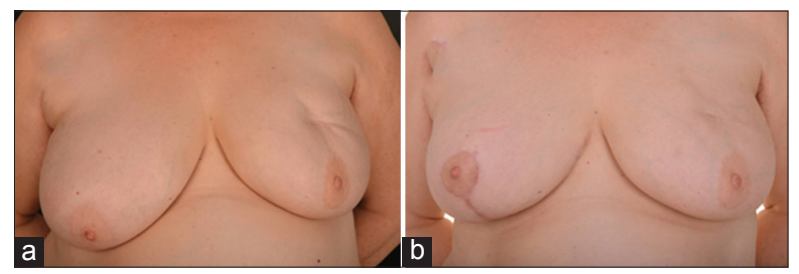

Figure 22: Symmetrisation surgery (a) Pre-operative (previous left breast conserving treatment) and (b) post-operative (left breast lipomodelling and right breast mastopexy) the need for more extensive autologous surgery. The advantages include reduced operative times (2-3 h), less stay in hospital (2-3 days), quick post-operative recovery (2-3 week), no donor site morbidity and less delays in adjuvant treatment. The implant is usually placed in the subpectoral/subfascial pocket.

\section{Types of implants}

There are three types of prosthesis/implants used; tissue expander, fixed volume implant and expander-implant [Table 6]. In two-stage operations, tissue expander is used in the first stage in the submuscular pocket. It is then slowly inflated with saline during outpatient appointments every 2-3 weeks. This slowly stretches the muscle and overlying skin. Once desirable volume/size is achieved, the second stage surgery is done replacing the tissue expander with the definitive implant. In selected women with smaller size breast, one-stage reconstruction can be carried out with the help of the definitive implant. More recently tissue matrix usually derived from the acellular dermal matrix (ADM) has been used to facilitate onestage breast reconstruction in moderate to even large size breasts. The newer expander-implants are versatile providing benefits of the two types mentioned above. They have an outer shell made of silicone constituting 35 or $50 \%$ of the total prosthesis and a central cavity, connected to a subcutaneous port. Initially, this central cavity is kept almost empty to facilitate tension-free healing of the overlying muscle and skin flaps. Then gradually the implant is inflated, and finally, the port is

Table 6: Types of breast reconstruction

\begin{tabular}{l|l|l}
\hline Type & Method & Process \\
\hline \multirow{2}{*}{ Implant-based } & One-stage & Fixed volume implant \\
\cline { 3 - 3 } & & Expander-implant \\
\cline { 3 - 3 } & \multirow{2}{*}{ Two-stage } & Tissue expander \\
\cline { 3 - 3 } & & Followed by fixed \\
\cline { 3 - 3 } & & volume implant \\
\hline \multirow{2}{*}{ Autologous } & \multirow{2}{*}{ Pedicled flap } & LD Flap \\
\cline { 3 - 3 } & & TRAM Flap \\
\cline { 2 - 3 } & \multirow{2}{*}{ Free flap } & DIEP Flap \\
\cline { 3 - 3 } & & SGAP/IGAP Flap \\
\hline
\end{tabular}

LD: Latissimus dorsi, TRAM: Transverse rectus abdominis muscle, DIEP: Deep inferior epigastric perforator, SGAP: Superior gluteal artery perforator, IGAP: Inferior gluteal artery perforator 
removed under local anaesthesia. This implant is kept permanently. ${ }^{[50-52]}$

\section{Types of reconstructive mastectomies}

There are three types of reconstructive mastectomies [Table 7]. The factors that help in deciding between various types include breast volume, cancer size/proximity to the NAC, need for adjuvant radiotherapy and patient expectations. Women with small to medium breast size (cup size A-B) are usually suitable for skin-sparing mastectomy (SSM), whereas larger volume breasts (cup size D and above) are offered skin reducing mastectomy (SRM).

\section{SSM}

This is the most commonly performed type of reconstructive mastectomy. A circumareolar incision is made usually with an ellipse of skin towards medial and lateral ends. Skin incision can be extended further laterally to facilitate axillary lymph node dissection through the same incision. Skin flaps are raised all around and are used for reconstruction, hence the name skin sparing. Mastectomy with/without axillary surgery is carried out. ${ }^{[53-55]}$

Submuscular pocket is created by lifting the lateral edge of pectoralis major all the way to the IMF. The lower fibres of the muscle are then dissected towards the medial end of the IMF. The laterally anterior fascia of the serratus anterior is elevated. An appropriate size breast expanderimplant is selected and placed in this submuscular pocket, closing the two muscles together to achieve an almost complete muscle cover for the prosthesis. Inferomedially, the expander-implant bottom lies in the subcutaneous planes of the IMF which helps in creating breast ptosis. The overlying skin is closed as a small transverse/oblique scar, with drain(s) secured within the post-operative bra ${ }^{[56]}$ [Figures 23 and 24].

\section{Table 7: Types of reconstructive mastectomies}

\begin{tabular}{l|l}
\hline Surgery & Description \\
\hline SSM & Breast skin is spared, sacrificing the NAC \\
\hline NSM & Breast skin as well as NAC are spared \\
\hline SRM & Reduction pattern, using inferior pole dermal sling \\
\hline
\end{tabular}

NAC: Nipple-areola complex, SSM: Skin-sparing mastectomy, NSM: Nipple-sparing mastectomy, SRM: Skin reducing mastectomy
Alternatively a definitive implant can be used in subpectoral plane helped by an ADM that works as a sling sutured to deeper tissues of the IMF as well as to the lateral/inferior edge of the pectoralis major.

\section{Nipple-sparing mastectomy (NSM)}

This is a modification of SSM and only offered in carefully selected patients, where cancer is $>2 \mathrm{~cm}$ away from the $\mathrm{NAC}$, and the total height of the breast is not $>10-12 \mathrm{~cm}$. Most favored incision is a $10 \mathrm{~cm}$ long incision in the lateral part of the IMF, other variation includes a lateral radial incision. Mastectomy and reconstructive procedure is the same as SSM; however, the tissue behind the NAC is carefully dissected with scissors/knife avoiding diathermy
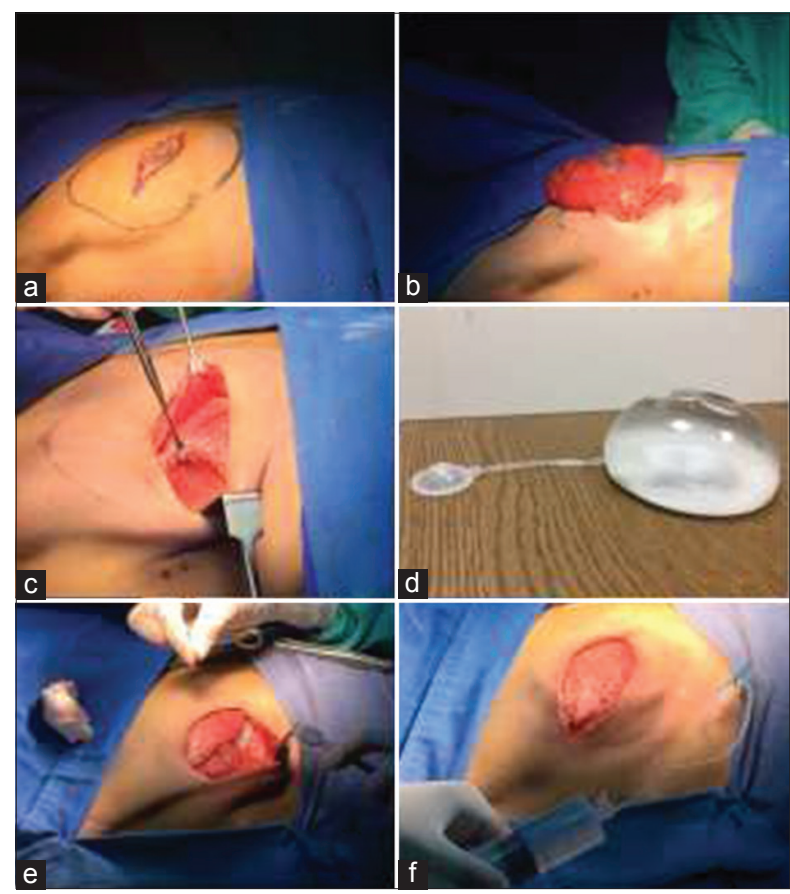

Figure 23: (a-f) Skin-sparing mastectomy and immediate reconstruction with tissue expander

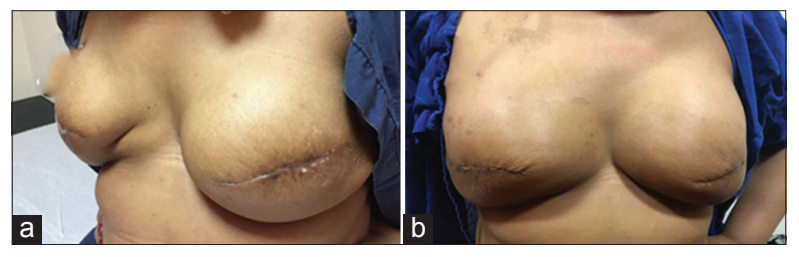

Figure 24: Bilateral skin-sparing mastectomy and two-stage reconstruction (a) post-tissue expander inflation, (b) postoperative exchange of tissue expander to definitive implant 
and sent separately for histopathology to confirm oncological clear margins ${ }^{[57-61]}$ [Figures 25 and 26].

\section{SRM}

Wise pattern incision is chosen for SRM in women agreeing to have a slightly smaller reconstructed breast. This is usually carried out in patients with large/ ptotic breasts, to give them an added advantage of breast reduction. However, this obligates the need for contralateral reduction mastopexy. After skin incision, the inferior pole of skin is de-epithelialised to create a dermal sling. Upper medial and lateral skin flaps are raised, followed by raising the inferior skin flap, which essentially is the deep dermis only. Then mastectomy is carried out along with the central overlying NAC complex.

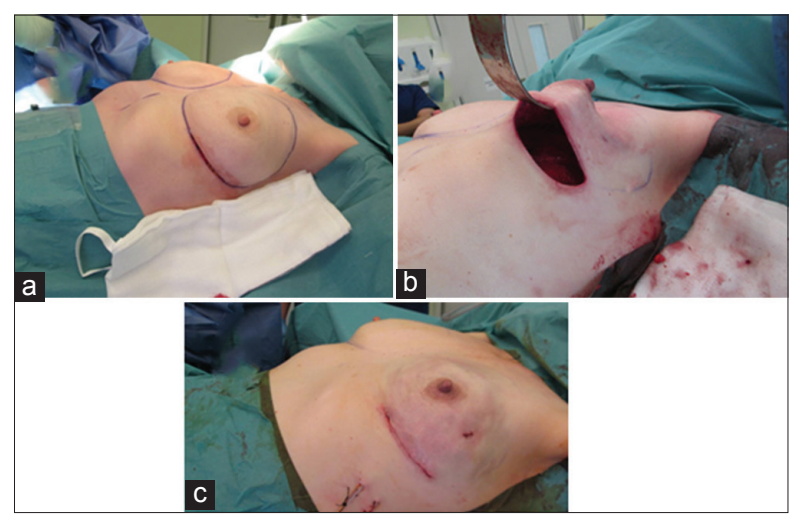

Figure 25: (a-c) Nipple-sparing mastectomy procedure with reconstruction

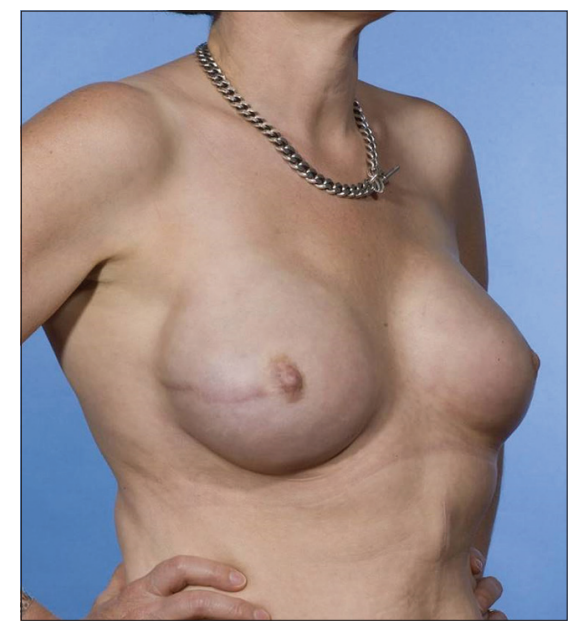

Figure 26: Post-operative bilateral nipple-sparing mastectomy and reconstruction
Finally, reconstruction is performed most commonly with the help of definitive implant placed in the submuscluar pocket, where pectoralis major lateral/inferior edge is sutured to the dermal sling providing complete implant cover. Overlying medial and lateral skin flaps are sutured together to the skin in the IMF, creating an inverted T-shaped wound [Figures 27 and 28].

\section{Complications of implant-based reconstruction}

Implant-based reconstruction is generally considered safe and is well tolerated by the majority. There are minor risks of skin wound infection, seroma and pain. The two significant immediate complications include prosthesis infection (5\%) and partial skin flap necrosis (7\%). Both of these are aggressively treated with intravenous antibiotics and skin dressing/debridement. However, in up to $10 \%$ of patients, these lead to explantation. ${ }^{[24]}$ Long-term complications include capsular contraction, asymmetry, implant rupture and implant creasing/ wrinkling. ${ }^{[62,63]}$ Table 8 provides a list of implant-related complications.

\section{Autologous Breast Reconstruction}

Autologous breast reconstruction provides a superior cosmetic outcome than the implant-based reconstruction. This is because the tissue reacts to gravity, aging and weight changes more naturally. However, it is associated with longer operative times $(6-8 \mathrm{~h})$, more stay in hospital (6-8 days), longer post-operative recovery (6-8 week), donor site morbidity and possible delays in the adjuvant treatment.

\section{Table 8: Complications of implant-based reconstruction}

\begin{tabular}{l|l}
\hline 1 & Wound infection \\
\hline 2 & Seroma \\
\hline 3 & Pain \\
\hline 4 & Prosthesis infection \\
\hline 5 & Partial skin flap necrosis \\
\hline 6 & Explantation \\
\hline 7 & Capsular contraction \\
\hline 9 & Asymmetry \\
\hline 10 & Implant rupture \\
\hline
\end{tabular}




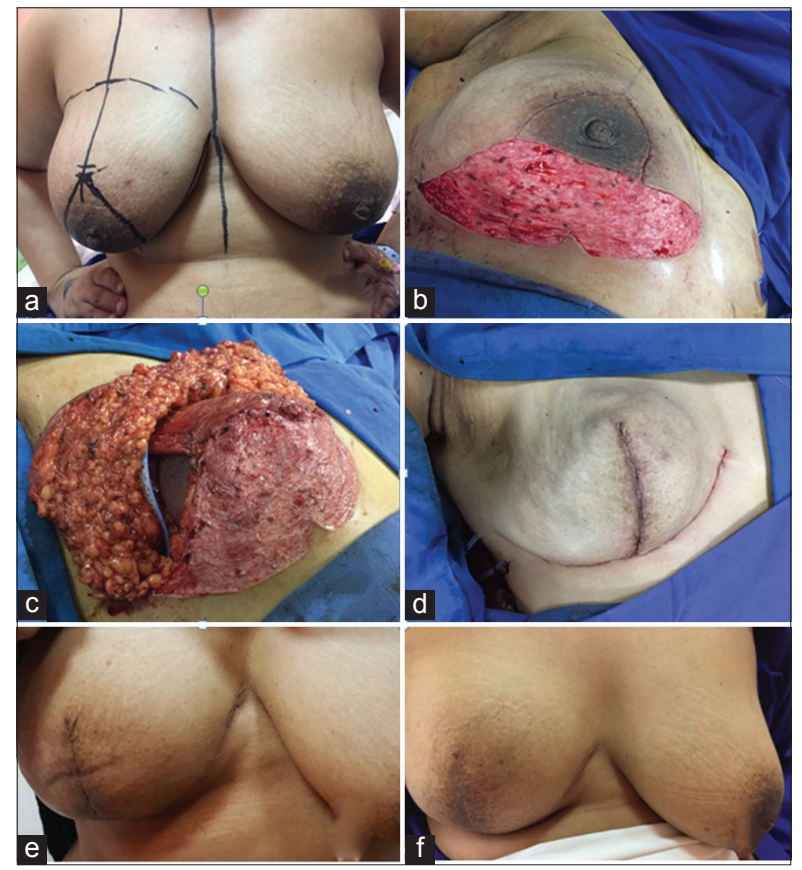

Figure 27: (a-e) Skin reducing mastectomy procedure

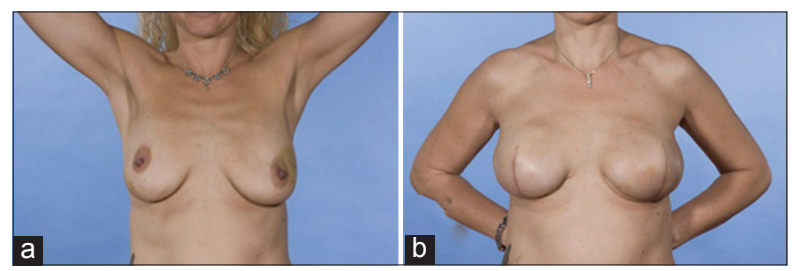

Figure 28: Skin reducing mastectomy (a) pre-operative and (b) post-operative

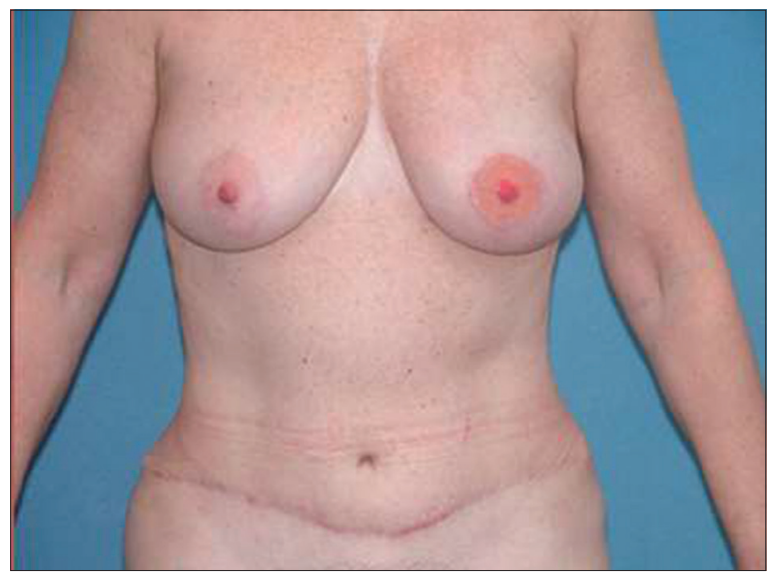

Figure 29: Deep inferior epigastric perforator autologous flap breast reconstruction
There are two ways of autologous breast reconstruction [Table 6]. Pedicled flaps remain attached to their blood supply at one end and most commonly utilize the LD flap, described earlier in volume replacement OPS techniques.

\section{Deep inferior epigastric perforator (DIEP) autolo- gous flap breast reconstruction}

The free flap is completely detached from the donor site along with its blood vessels and then re-attached within the reconstructed breast with the help of vascular anastomosis. Most common free flap for breast reconstruction is DIEP flap. It completely spares the rectus abdominis muscle minimizing the risk of abdominal wall hernia. It is based on the DIEP artery which is carefully dissected and then re-anastomosed to the branch of the internal mammary artery through intercostal space. The donor tissue is sutured to the chest wall while moulding it into a breast shape covered by native breast skin and brining extra skin from the abdomen [Figure 29]. ${ }^{[64-67]}$

\section{Conclusion}

The OPS has brought a revolution in extending the boundaries of what can be offered with the BCT. It should be offered to appropriately selected patients where careful surgical planning is mandatory. Tumour size and location within the breast are the most important factors in the selection of the most suitable oncoplastic surgical technique including volume displacement and replacement. The OPS has proven benefits. Symmetrisation of the contralateral breast should be offered to patients undergoing such surgeries. For women undergoing mastectomy, the option of immediate or delayed reconstruction should always be discussed with the patient.

Professor Umberto Veronesi once said 'Women aware of breast cancer issues and who participate in early detection programmes should be rewarded with gentle and appropriate care and not punished with heavy and often unjustified treatments. ${ }^{968,69]}$

\section{Conflict of Interest}

The authors declare that they have no conflict of interest. 


\section{References}

1. Veronesi U, Cascinelli N, Mariani L, et al. Twenty-year follow-up of a randomized study comparing breastconserving surgery with radical mastectomy for early breast cancer. N Engl J Med 2002;347:1227-32.

2. Doridot V, Nos C, Aucouturier JS, et al. Breast-conserving therapy of breast cancer. Cancer Radiother 2004;8:21-8.

3. Fisher B, Dignam J, Wolmark N, et al. Lumpectomy and radiation therapy for the treatment of intraductal breast cancer: Findings from national surgical adjuvant breast and bowel project. J Clin Oncol 1998;16:441-52.

4. Jakesz R, Samonigg H, Gnant M, et al. Significant increase in breast conservation in 16 years of trials conducted by the Austrian breast and colorectal study group. Ann Surg 2003;237:556-64.

5. Urban C, Lima R, Schunemann E, et al. Oncoplastic principles in breast conserving surgery. Breast 2011;20 Suppl 3:S92-5.

6. Clough $\mathrm{KB}$, Kaufman $\mathrm{GJ}$, Nos $\mathrm{C}$, et al. Improving breast cancer surgery: A classification and quadrant per quadrant atlas for oncoplastic surgery. Ann Surg Oncol 2010;17:1375-91.

7. Baildam AD. Oncoplastic surgery for breast cancer. Br J Surg 2008;95:4-5.

8. Clough KB, Soussaline M, Campana F, et al. Mammoplasty combined with irradiation: Conservative treatment of breast cancer localized in the lower quadrant. Ann Chir Plast Esthet 1990;35:117-22.

9. Cothier-Savey I, Otmezguine Y, Calitchi E, et al. Value of reduction mammoplasty in the conservative treatment of breast neoplasm. A propos of 70 cases. Ann Chir Plast Esthet 1996;41:346-53.

10. Petit JY, Rietjens M, Garusi C, et al. Integration of plastic surgery in the course of breast-conserving surgery for cancer to improve results and radicality of tumor excision. Recent Results Cancer Res 1998;152:202-11.

11. Spear SL, Pelletiere CV, Wolfe AJ, et al. Experience with reduction mammoplasty combined with breast conservation therapy in the treatment of breast cancer. Plast Reconstr Surg 2002;111:1102-9.

12. Anderson BO, Masetti R, Silverstein MJ. Oncoplastic approaches to partial mastectomy: An overview of volumedisplacement techniques. Lancet Oncol 2005;6:145-57.

13. Masetti R, Pirulli PG, Magno S, et al. Oncoplastic techniques in the conservative surgical treatment of breast cancer. Breast Cancer 2000;7:276-80.

14. Franceschini G, Terribile D, Magno S, et al. Update on oncoplastic breast surgery. Eur Rev Med Pharmacol Sci 2012;16:1530-40.

15. Audretsch W. Space-holding technic and immediate reconstruction of the female breast following subcutaneous and modified radical mastectomy. Arch Gynecol Obstet 1987;241 Suppl: S11-9.

16. Clough KB, Lewis JS, Couturaud B, et al. Oncoplastic techniques allow extensive resections for breast- conserving therapy of breast carcinomas. Ann Surg 2003;237:26-34.

17. Association of Breast Surgery at BASO, Association of Breast Surgery at BAPRAS, Training Interface Group in Breast Surgery, et al. Oncoplastic breast surgery-a guide to good practice. Eur J Surg Oncol 2007;33 Suppl 1:S1-23.

18. Berman RS, Weigel RJ. Training and certification of the surgical oncologist. Chin Clin Oncol 2014;3:45.

19. MacNeill F. Training in breast reconstruction. Hosp Med 2004;65:124.

20. Baildam AD. Oncoplastic surgery of the breast. Br J Surg 2002;89:532-3.

21. Rainsbury RM. Training and skills for breast surgeons in the new millennium. ANZ J Surg 2003;73:511-6.

22. Parvaiz MA, Yang P, Razia E, et al. Breast MRI in invasive lobular carcinoma: A useful investigation in surgical planning? Breast J 2016;22:143-50.

23. Parvaiz MA, Isgar B. Incidental breast lesions detected on diagnostic CT scans: A 4-year prospective study. Breast J 2013; 19:457-9.

24. Franceschini G, Magno S, Fabbri C, et al. Conservative and radical oncoplastic approches in the surgical treatment of breast cancer. Eur Rev Med Pharmacol Sci 2008;12:387-96.

25. Nahabedian MY. Oncoplastic Surgery of the Breast. Ch. 4. Philadelphia, PA: Saunders Elsevier; 2009. p. 23-45.

26. Colombo G, Dellacasa I, Ruvolo V, et al. Oncoplastic surgery for the treatment of breast cancer. Minerva Ginecol 2009;61:439-44.

27. Lebovic GS. Oncoplastic surgery: A creative approach to breast cancer management. Surg Oncol Clin N Am 2010;19:567-80.

28. Gainer SM, Lucci A. Oncoplastics: Techniques for reconstruction of partial breast defects based on tumor location. J Surg Oncol 2011;103:341-7.

29. Bous A, Nardella D, Maweja S, et al. Breast oncoplastic surgery. Rev Med Liege 2011;66:341-50.

30. Hamdi M. Oncoplastic and reconstructive surgery of the breast. Breast 2013;22 Suppl 2:S100-5.

31. Benelli L. A new periareolar mammaplasty: The "round block" technique. Aesthetic Plast Surg 1990;14:93-100.

32. McCulley SJ, Durani P, Macmillan RD. Therapeutic mammaplasty for centrally located breast tumors. Plast Reconstr Surg 2006;117:366-73.

33. Galimberti V, Zurrida S, Zanini V, et al. Central small size breast cancer: How to overcome the problem of nipple and areola involvement. Eur J Cancer 1993;29A:1093-6.

34. Lejour M, Abboud M, Declety A, et al. Reduction of mammaplasty scars: From a short inframammary scar to a vertical scar. Ann Chir Plast Esthet 1990;35:369-79.

35. Masetti R, Di Leone A, Franceschini G, et al. Oncoplastic techniques in the conservative surgical treatment of breast cancer: An overview. Breast J 2006;12:S174-80.

36. Fitzal F. Oncoplastic surgery: A rolling stone gathers no moss. Breast 2010;19:437-8.

37. Cardoso MJ, Macmillan RD, Merck $\mathrm{B}$, et al. Training 
in oncoplastic surgery: An international consensus. The $7^{\text {th }}$ Portuguese senology congress, vilamoura, 2009. Breast 2010;19:538-40.

38. Liem AA, Iqbal A. Oncoplastic breast surgery in Britain. Plast Reconstr Surg 2011;127:1012-3.

39. Dixon JM, Venizelos B, Chan P. Latissimus dorsi miniflap: A technique for extending breast conservation. Breast 2002; 11:58-65.

40. Kat CC, Darcy CM, O'Donoghue JM, et al. The use of the latissimus dorsi musculocutaneous flap for immediate correction of the deformity resulting from breast conservation surgery. Br J Plast Surg 1999;52:99-103.

41. Losken A, Dugal CS, Styblo TM, et al. A meta-analysis comparing breast conservation therapy alone to the oncoplastic technique. Ann Plast Surg 2014;72:145-9.

42. Mariani L, Salvadori B, Marubini E, et al. Ten year results of a randomised trial comparing two conservative treatment strategies for small size breast cancer. Eur J Cancer 1998;34:1156-62.

43. Amichetti M, Busana L, Caffo O. Long-term cosmetic outcome and toxicity in patients treated with quadrantectomy and radiation therapy for early-stage breast cancer. Oncology 1995;52:177-81.

44. Giacalone PL, Roger P, Dubon O, et al. Comparative study of the accuracy of breast reconstruction in oncoplastic surgery and quadrantectomy in breast cancer. Ann Surg Oncol 2006;14:605-14.

45. van Paridon MW, Kamali P, Paul MA, et al. Oncoplastic breast surgery: Achieving oncological and aesthetic outcomes. J Surg Oncol 2017;116:195-202.

46. Rainsbury RM. Surgery insight: Oncoplastic breast conserving reconstruction-indications, benefits, choices and outcomes. Nat Clin Pract Oncol 2007;4:657-64.

47. Skillman JM, Humzah MD. The future of breast surgery: A new subspecialty of oncoplastic breast surgeons? Breast 2003;12:161-2.

48. Berry MG, Fitoussi AD, Curnier A, et al. Oncoplastic breast surgery: A review and systematic approach. J Plast Reconstr Aesthet Surg 2010;63:1233-43.

49. Goh SC, Martin NA, Pandya AN, et al. Patient satisfaction following nipple-areolar complex reconstruction and tattooing. J Plast Reconstr Aesthet Surg 2011;64:360-3.

50. Goh SC, Thorne AL, Williams G, et al. Breast reconstruction using permanent Becker expander implants: An 18 year experience. Breast 2012;21:764-8.

51. Tasoulis MK, Iqbal FM, Cawthorn S, et al. Subcutaneous implant breast reconstruction: Time to reconsider? Eur J Surg Oncol 2017;43:1636-46.

52. Muscara F, Parvaiz MA, Rusby JE. A simple technique of breast tissue expander saline aspiration. Ann R Coll Surg Engl 2015;97:476.

53. Salgarello M, Farallo E. Immediate breast reconstruction with definitive anatomical implants after skin sparing mastectomy. Br J Plast Surg 2005;58:216-22.

54. Spear SL, Pellettiere CV. Immediate breast reconstruction in two stages using textured, integrated valve tissue expanders and breast implants. Plast Reconstr Surg 2004;113:2098-103.

55. Gendy RK, Able JA, Rainsbury RM. Impact of skin sparing mastectomy with immediate reconstruction and breastsparing reconstruction with mini flaps on the outcomes of oncoplastic breast surgery. Br J Surg 2003;90:433-9.

56. Bradbury C, Parvaiz MA, Sircar T. Innovative postoperative bra for patients with drains following breast surgery. Ann R Coll Surg 2014;96:241.

57. Simmons RM, Hollenbeck ST, Latrenta GS. Areola-sparing mastectomy with immediate breast reconstruction. Ann Plast Surg 2003;51:547-51.

58. Simmons RM, Hollenbeck ST, Latrenta GS. Two-year follow-up of areola-sparing mastectomy with immediate reconstruction. Am J Surg 2004;188:403-6.

59. Vlajcic Z, Zic R, Stanec S, et al. Nipple-areola complex preservation: Predictive factors of neoplastic nipple-areola complex invasion. Ann Plast Surg 2005;55:240-4.

60. Rusby JE, Smith BL, Gui GP. Nipple-sparing mastectomy. Br J Surg 2010;97:305-16.

61. Rusby JE, Kirstein LJ, Brachtel EF, et al. Nipple-sparing mastectomy: Lessons from ex vivo procedures. Breast J 2008;14:464-70.

62. Momoh AO, Ahmed R, Kelley BP, et al. A systematic review of complications of implant-based breast reconstruction with prereconstruction and postreconstruction radiotherapy. Ann Surg Oncol 2014;21:118-24.

63. Di Micco R, O'Connell RL, Barry PA, et al. Bilateral mammoplasty for cancer: Surgical, oncological and patientreported outcomes. Eur J Surg Oncol 2017;43:68-75.

64. Allen RJ, Treece P. Deep inferior epigastric perforator flap for breast reconstruction. Ann Plast Surg 1994;32:32-8.

65. Blondeel PN. One hundred free DIEP flap breast reconstructions: A personal experience. Br J Plast Surg 1999;52:104-11.

66. Hamdi M, Weiler-Mithoff EM, Webster MH. Deep inferior epigastric perforator flap in breast reconstruction: Experience with the first 50 flaps. Plast Reconstr Surg 1999;103:86-95.

67. Granzow JW, Levine JL, Chiu ES, et al. Breast reconstruction with the deep inferior epigastric perforator flap: History and an update on current technique. J Plast Reconstr Aesthet Surg 2006;59:571-9.

68. Pillarisetti RR, Querci Della Rovere G. Oncoplastic breast surgery. Indian J Surg 2012;74:255-63.

69. Nina H, Xhepa G, Xh C, et al. Use of ocoplastic surgery in patients with breast cancer. Int J Educ Sci Technol Innov Health Environ 2016;2:104-12. 